\title{
FORMAÇÃO CONTINUADA DO PROFESSOR E A CONTRIBUIÇÃO PARA APRIMORAMENTO DA QUALIDADE NO PROCESSO ENSINO E APRENDIZAGEM.
}

Flávia Maria Albertino, Carmen Lúcia Dias.

Universidade do Oeste Paulista - UNOESTE, Mestrado em Educação, Presidente Prudente, SP. E-mail: fmalbertino@hotmail.com.

\section{RESUMO}

Mudanças se fazem necessárias na educação para promover um ensino de qualidade, assim como a formação continuada do professor é primordial no processo de ensino e aprendizagem. Este estudo objetivou analisar a formação continuada do professor e refletir as suas contribuições para o processo de ensino e aprendizagem e para a própria prática pedagógica do professor. Para atingir tal objetivo, utilizou-se a pesquisa bibliográfica com autores que se dedicaram a analisar e refletir sobre o tema. Os resultados apontam a importância do constante aperfeiçoamento, atualização e bom preparo dos professores, sendo a formação contínua uma das formas mais eficazes para estudar e compreender todo o processo de ensino e aprendizagem. Concluímos que o professor precisa estar bem preparado para a mediação pedagógica, o aprimoramento e atualização com a formação continuada do professor contribui e favorece a aprendizagem do aluno, valorizando a diversidade e a característica única que possui cada sujeito.

Palavras-chave: Formação continuada. Ensino e Aprendizagem. Prática pedagógica.

\section{CONTINUED TRAINING OF THE TEACHER AND THE CONTRIBUTION FOR THE ENHANCEMENT OF QUALITY IN THE PROCESS TEACHING AND LEARNING.}

\begin{abstract}
Changes are necessary in education to promote quality teaching, just as continuing teacher training is paramount in the teaching and learning process. This study aimed to analyze the teacher's continuing education and to reflect his contributions to the teaching and learning process and to the teacher's own pedagogical practice. In order to reach this objective, bibliographical research was used with authors who dedicated themselves to analyzing and reflecting on the theme. The results point to the importance of constant improvement, updating and good preparation of teachers, with continuing education being one of the most effective ways to study and understand the entire teaching and learning process. We conclude that the teacher needs to be well prepared for pedagogical mediation, the improvement and updating with the continued teacher training contributes and favors student learning, valuing the diversity and the unique characteristic that each subject possesses.
\end{abstract}

Keywords: Continuing education. Teaching and learning. Pedagogical practice. 


\section{INTRODUÇÃO}

A aprendizagem é fundamental na vida do ser humano, na qual o professor torna-se indispensável em todo o processo de ensino e aprendizagem, do mesmo modo, a interação entre professor e aluno possui um valor pedagógico explícito, tornando-se um processo colaborativo para um bom ensino. Nessa perspectiva Mello (2004, p.144) ressalta "Por isso, para Vygotsky, o bom ensino é aquele que garante aprendizagem e impulsiona o desenvolvimento. Nesse sentido, o bom ensino acontece num processo colaborativo entre educador e a criança [...]".

Em busca de uma educação de qualidade e para contribuir nesse processo colaborativo, segundo Delors (2012), a prática pedagógica deve preocupar-se em desenvolver quatro aprendizagens fundamentais que são formadores e sustentadores da prática educativa do professor e aprendizagem do educando, que serão para cada indivíduo os pilares do conhecimento: Aprender a conhecer: aprendizagem dos científicos e culturais que ajudam a distinguir o que é real e o que é ilusório e a ter assim acesso inteligente aos saberes de nossa época. Neste contexto, o espírito científico como aquisição fundamental da aventura humana é indispensável. Aprender a conhecer também significa ser capaz de estabelecer pontes entre os diferentes saberes, entre esses saberes e seus significados para nossa vida cotidiana; Aprender a fazer: ação sobre o meio envolvente, um aprendizado da criatividade, mostrando nossas potencialidades para de fato participar e ser parceiro na prática pedagógica do professor; Aprender a viver juntos: respeito às normas que regem as relações entre os seres que compõem uma coletividade, segundo o expresso no relatório da Unesco; Aprender a ser: o ser humano integral é aquele que já tem consciência da responsabilidade como dever e da liberdade como direito. Tem consciência de sua utilidade individual e social, age e interage com base não só no conhecimento, mas também no autoconhecimento.

Assim, o professor é o preceptor da preparação do desenvolvimento e de todo processo de ensino e aprendizagem do seu aluno e tem a incumbência de promover um ensino de qualidade, de facilitar a aprendizagem, de conduzir as aulas de maneira dinâmica e prazerosa demonstrando domínio de conteúdo, de incitar o poder de argumentação - "despertando" o aluno crítico e reflexivo-, de ser eficiente e eficaz ao ministrar sua aula e ter a percepção da necessidade da formação contínua. Para mediar a aprendizagem do aluno, é necessário ao professor estar capacitado, qualificado, capaz de propiciar ao seu aluno competências e habilidades necessárias para o seu desenvolvimento e a sua formação.

Muitas vezes, em sala de aula, nos deparamos com alunos e suas dificuldades diante do processo de ensino e de aprendizagem. As dificuldades de aprendizagem podem decorrer de diversos fatores, sejam orgânicos ou emocionais. É importante que todos os atores envolvidos no processo educativo estejam atentos a essas dificuldades, em específico o professor. Por isso, a necessidade deste estar em contínua formação e apto para os encaminhamentos necessários, seja para procedimentos em sala de aula ou para especialistas da área.

Portanto, é relevante o estudo e reflexões na formação continuada do professor para que sua prática pedagógica esteja adequada, e assim favorecer o processo de ensino e de aprendizagem do aluno.

Assim, o objetivo deste estudo foi analisar a formação continuada do professor e refletir as contribuições que esta traz para o processo de ensino e de aprendizagem e para a própria prática pedagógica do professor.

\section{METODOLOGIA}

Esta pesquisa, de cunho bibliográfico (SALVADOR, 1991), teve como aporte teórico a revisão de literatura especializada sobre o tema em algumas obras de referência que compreendem os anos entre 1991 e 2012 e dois artigos (Luckesi, 2005 com acesso em 2016; Clebesch, 2007 com acesso em 2016), com autores que propõem algumas reflexões sobre a 
formação continuada do professor e a contribuição para o aprimoramento da qualidade no processo ensino e de aprendizagem.

\section{RESULTADOS}

Para obter a qualidade na educação, é preciso buscar o desenvolvimento e enriquecimento de competências. A formação profissional dos que se dedicam ao oficio de professor implica em entender essa formação como um processo contínuo para contribuir não somente com o professor, mas como no processo ensino e aprendizagem do aluno.

Por essa ótica, formação assume uma posição de 'inacabamento', vinculada à história de vida dos sujeitos em permanente processo de formação, que proporciona a preparação profissional. O processo de formação é multifaceado, plural, tem início e nunca tem fim. É inconcluso e autoformativo [...] (VEIGA, 2008, p. 15).

Desse modo, a formação contínua traz melhorias para a prática pedagógica do professor, assim como a postura reflexiva deste profissional em sua ação. Conforme Zeichner (1993, p. 20), "[...] a reflexão é um processo que ocorre antes e depois da acção e, em certa medida, durante a acção [...] Schon chamou-Ihe reflexão na acção [...]".

A reflexão se faz necessária ao processo de ensino e de aprendizagem, criando e favorecendo as estratégias de ensino que amplia e colabora com o desenvolvimento e a aprendizagem do aluno. Se o ensino que se almeja é tornar o aluno crítico reflexivo, propiciando sua autonomia, é preciso que o professor tenha essa postura. Segundo Libâneo (2006, p.76) "Se queremos um aluno crítico reflexivo, é preciso um professor crítico reflexivo".

O professor reflexivo reflete sobre sua própria relação com o saber, assim como reflete sobre sua forma de superar as limitações em sala de aula e tornar sua prática pedagógica mais eficaz, construindo novos conhecimentos, criando situações-problema que proporcionem uma verdadeira aprendizagem, transformando a ação docente em uma intervenção adaptada, frente a uma necessidade emergente no contexto educacional e diante das características e diferenças peculiares de cada aluno que há em uma sala de aula.

Portanto Zabala $(1998$, p. 34) aponta que:

O fato de que não exista uma única corrente psicológica, nem consenso entre as diversas correntes existentes, não pode nos fazer perder de vista que há uma série de princípios nos quais as diferentes correntes estão de acordo: as aprendizagens dependem das características singulares de cada um dos aprendizes; correspondem, em grande parte, às experiências que cada um viveu desde o nascimento; a forma como se aprende e o ritmo da aprendizagem variam segundo as capacidades, motivações e interesses de cada um dos meninos e meninas; enfim, a maneira e a forma como se produzem as aprendizagens são o resultado de processos que sempre são singulares e pessoais.

O professor ao planejar precisa adequar sua proposta aos interesses do aluno e aos resultados gerados. Avaliar a intervenção pedagógica torna-se igualmente uma formação contínua e permite ao professor melhorar sua atuação em sala de aula.

O aperfeiçoamento da prática educativa é o objetivo básico de todo educador. $\mathrm{E}$ se entende este aperfeiçoamento como meio para que todos os alunos consigam o maior grau de competências, conforme suas possibilidades reais. $\mathrm{O}$ alcance dos objetivos por parte de cada aluno é um alvo que exige conhecer os resultados e os processos de aprendizagem que os alunos seguem. E para melhorar a qualidade do ensino é preciso 
conhecer e poder avaliar a intervenção pedagógica dos professores, de forma que a ação avaliadora observe simultaneamente os processos individuais e os grupais. Referimo-nos tanto aos processos de aprendizagem como aos de ensino, já que, desde uma perspectiva profissional, o conhecimento de como os meninos e meninas aprendem é, em primeiro lugar, um meio para ajuda-lo em seu crescimento e, em segundo lugar, é o instrumento que tem que nos permitir melhorar nossa atuação em sala de aula. (ZABALA, 1998, p. 201).

Nos contextos atuais da educação, é preciso perceber que, o professor necessita permanecer em formação contínua, refletir, avaliar sua prática, revisar, organizar e atualizar-se sempre como um sujeito crítico-reflexivo. O professor que apenas ensina será substituído pelos sistemas informatizados. Nessa perspectiva, Demo (1993, p. 155) afirma: “[...] o professor que apenas ensina vai tornando-se sucata."

As mudanças se fazem necessárias na educação, nas escolas e principalmente nas salas de aula, a busca pela atualização, a formação contínua do professor no processo de auto formação, depende de cada um, é de suma importância a vontade e a capacidade para facear as mudanças para que sejam executadas e favoreçam o desenvolvimento e a aprendizagem.

[...] Certamente que não temos, de imediato, nenhuma possibilidade de mudar as políticas públicas para a educação, assim como as condições materiais de ensino, tais como baixos salários, espaços físicos inadequados, entre outros. Essas são reivindicações que exigem ações nossas no âmbito da sociedade civil organizada, como sindicatos, partidos políticos, comunidades de base. Todavia, na nossa sala de aula, podemos colocar nossa atenção e nosso coração naquilo que praticamos, tais como no desejo de que os alunos aprendam, na criação ou recriação de atividades que possibilitem, no processo prazeroso e criativo de aprendizagem, na relação com os educandos, que, por conseqüência, possibilitam o desenvolvimento. (LUCKESI, 2005, p. 2).

A formação de professores é um processo contínuo e que contribui na qualidade do processo de ensino e aprendizagem. Um professor que sempre busca de uma boa formação, está preparado e mais seguro e motivado para o seu ofício.

Assim, ensinar e motivar os alunos a aprender pode envolver uma série de questões. A primeira delas é quanto ao preparo, à formação de educadores. Até onde esta os habilita e os assegura para que, nesse processo, suas ações se firmem em planejamentos coerentes com a realidade que os cerca? Para que ensinar? Quem é este aluno para quem se ensina? São algumas indagações precisas e adjuntas do ato de ensinar e que a boa formação pode colaborar para que alguns passos sejam dados ao encontro dessas respostas. Um professor mais preparado e seguro do seu papel pode estar mais motivado a ensinar. (PILETTI; ROSSATO, 2011, p.163).

O aperfeiçoamento da prática pedagógica é construído a partir da formação contínua e de uma ação consciente do professor como um profissional reflexivo, agente de sua própria formação, mediando a construção do conhecimento com atividades significativas para promover no aluno suas potencialidades, capacidades e uma consciência cidadã, possibilitando tornarem-se sujeitos participantes, autônomos e críticos. 


\section{DISCUSSÃO}

A escola junto ao corpo docente deve oferecer situações que favoreçam - e não que dificultem a aprendizagem. Se o professor não está preparado e qualificado para atuar no processo educativo, os alunos não terão como aprender.

O ensino da atualidade exige mudanças, atualizações e aperfeiçoamentos para enfrentar os desafios presentes na prática pedagógica. Segundo Brzezinski (apud HYPOLITTO, 2007, p. 1). "uma sólida formação científica, técnica e política, viabilizadora de uma prática pedagógica crítica e consciente da necessidade de mudanças na sociedade brasileira".

A pesquisa e o estudo constante são relevantes ao professor. Clebesch $(2007$, p. 1) aponta: $\mathrm{Na}$ velocidade que as coisas estão mudando é nosso dever pensar um pouco mais para onde estamos indo e levando conosco nossos estudantes. Precisamos sair da toca. Não somos mais apenas professores. Somos, também analistas de tendências. $E$ isso é muito estimulante. Devemos entender melhor o mundo para dialogarmos melhor com ele. [...] deixemos nossas tocas. Quem hiberna são os ursos. Muitos deles, aliás, estão ameaçados de extinção.

Desse modo, a pesquisa deve ser concebida como característica essencial à prática pedagógica, e assim, contribuir na aprendizagem do aluno. Para Demo (1993, p. 128) "Quem pesquisa, tem o que ensinar, deve, pois, ensinar, porque "ensina" a produzir, não a copiar. Quem não pesquisa, nada tem a ensinar, pois apenas ensina a copiar".

Nesse sentido Freire (2011, p. 32) ressalta:

[...] Enquanto ensino continuo buscando, reprocurando. Ensino porque busco, porque indaguei, porque indago e me indago. Pesquiso para constatar, constatando, intervenho, intervindo educo e me educo. Pesquiso para conhecer o que ainda não conheço e comunicar ou anunciar a novidade.

Em busca de melhorar a realidade da educação, a prática em sala de aula e consequentemente o processo de ensino-aprendizagem, é necessário o constante aperfeiçoamento do professor. Silva $(1991$, p. 3) aponta:

Atualize-se, atualize-se, atualize-se... - esta repetição é intencional e pretende apagar da sua consciência algum possível resquício de desejo de acomodação. A chamada 1educação permanente' é fundamental para todos os indivíduos e mais fundamental ainda para os educadores. Além de uma dedicação maior à literatura de sua área específica de atuação, procure acompanhar e inter-relacionar os dados provindos de outros campos do conhecimento, principalmente história, política e economia. É o conhecimento da totalidade do real que aumenta o seu poder de julgamento e decisão. E os maiores beneficiados serão você mesmo e os seus alunos.

A flexibilidade frente às inúmeras informações atuais e conteúdos são importantes, para não tornar a sala de aula em um espaço rígido, engessando a aprendizagem e tornando os alunos desmotivados e desinteressados. O professor precisa despertar no aluno o desejo e a vontade de aprender cada vez mais.

[...] Temos informações demais e dificuldade em escolher quais são significativas para nós e conseguir integrá-las dentro da nossa mente e da nossa vida. A aquisição da informação, dos dados dependerá cada vez 
menos do professor. As tecnologias podem trazer hoje dados, imagens, resumos de forma rápida e atraente. O papel do professor - o papel principal - é ajudar o aluno a interpretar esses dados, a relacioná-los, a contextualizá-los. O papel do educador é mobilizar o desejo de que o aluno aprenda, que se sinta sempre com vontade de aprender, de conhecer mais. (MORAN, 2012, p. 33).

Nesse sentido a mediação/intervenção do professor é primordial, Mello (2004, p.144 -145) afirma: "[...] O educador deve, portanto, intervir, provocando avanços que de forma espontânea não ocorreriam [...] Em outras palavras, o processo de aprendizagem exige a atuação do adulto junto com a criança [...]".

Assim, para entender melhor o ato de aprender e o sujeito que aprende, é importante conhecer o processo de aprendizagem e considerar o ato de aprender na perspectiva do cognitivo, do social, do cultural, do afetivo/emocional. $O$ ato de aprender é complexo, demanda estudo, frente a tal diversidade e à característica única que possui cada sujeito.

[...] é uma construção contínua, comparável à edificação de um grande prédio que, à medida que se acrescenta algo, ficará mais sólido, ou à montagem de um mecanismo delicado, cujas fases gradativas de ajustamento conduziriam a uma flexibilidade e uma mobilidade das peças tanto maiores quanto mais estável se tornasse o equilíbrio [...]. (PIAGET,1999, p.14).

Portanto, é necessária a percepção de que é do ato de aprender que provem a aprendizagem de construção e aquisição do mundo que cerca o sujeito. Deste modo se constitui, fomentando a indissociabilidade entre o ato de aprender, o sujeito e a aprendizagem.

A formação contínua de professores é uma das formas mais eficazes para estudar e continuar a compreender todo o processo de ensino e aprendizagem, pois o professor precisa estar muito bem preparado para a mediação pedagógica e para ministrar uma aula que abrange pessoas com características peculiaridades, saberes, culturas e realidades diferentes.

Sem dúvida, é difícil conhecer os diferentes graus de conhecimento de cada menino e menina, identificar o desafio de que necessitam, saber que ajuda requerem e estabelecer a avaliação apropriada para cada um deles a fim de que se sintam estimulados a se esforçar em seu trabalho. Mas o fato de que custe não deve nos impedir de buscar meios ou formas de intervenção que, cada vez mais, nos permitam dar uma resposta adequada às necessidades pessoais de todos e cada um de nossos alunos (ZABALA, 1998, p. 36).

Não é fácil, como o senso comum às vezes pensa, que mesmo em meio aos desafios de uma sala de aula, o professor leciona com excelência. Para que isto ocorra, por mais que seja árduo, se faz necessário a formação continuada, a busca pela atualização e bom preparo dos professores.

\section{CONCLUSÃO}

Por meio deste estudo foi possível compreender o significativo ofício do professor, sua incumbência de promover um ensino de qualidade, facilitando a aprendizagem e despertando o aluno crítico e reflexivo.

É necessário ao professor estar capacitado, qualificado, para que sua prática pedagógica esteja adequada, favorecendo o processo de ensino e aprendizagem do aluno, propiciando competências e habilidades necessárias para o seu desenvolvimento e a sua formação. 
É de suma importância o constante aperfeiçoamento frente à realidade da educação, se faz necessário a busca pela atualização e bom preparo dos professores. A formação contínua é uma das formas mais eficazes para estudar e continuar a compreender todo o processo de ensino e aprendizagem.

Contudo, o professor precisa estar muito bem preparado para a mediação pedagógica e para ministrar uma aula que abrange pessoas com características peculiaridades, saberes, culturas e realidades diferentes. $O$ ato de aprender é complexo, demanda estudo, aprimoramento e atualização do professor para contribuir e favorecer a aprendizagem, valorizando a diversidade e a característica única que possui cada sujeito.

\section{REFERÊNCIAS}

CLEBESCH, J. Muito além do jardim. Profissão Mestre, Curitiba, Paraná, p. 4, abr. 2007. Disponível em: <www.profissaomestre.com.br>. Acesso: out. 2016.

DELORS, J. (Org.). Educação um tesouro a descobrir - Relatório para a Unesco da Comissão Internacional sobre Educação para o Século XXI. Editora Cortez, 7a edição, 2012.

DEMO, P. Desafios modernos da educação. Petrópolis, Vozes, 1993.

FREIRE, P. Pedagogia da Autonomia: saberes necessários à prática educativa. 43. ed. São Paulo: Paz e Terra, 2011.

HYPOLITTO, D. Repensando a formação continuada. A essência na formação contínua é a construção coletiva do saber e a discussão crítica. São Paulo, 2007. Disponível em:<http://br.geocities.com> Acesso em: nov. 2016.

LIBÂNEO, J. C. Reflexividade e formação de professores: outra oscilação do pensamento pedagógico brasileiro? In: PIMENTA, S. G.; GHEDIN, E. (Orgs.). Professor reflexivo no Brasil: gênese e crítica de um conceito. 4. ed. São Paulo: Cortez, 2006. p. 53-79.

LUCKESI, C. C. Formalidade e criatividade na prática pedagógica. Revista ABC EDUCATIO, n. 48, p.28-29, ago. 2005. Disponível em: < http://www.luckesi.com.br>. Acesso em: nov. 2016.

MELLO, S. A. A escola de Vygotsky. In: CARRARA, K. (Org.). Introdução à psicologia da educação: seis abordagens. São Paulo: Avercamp, 2004. p. 135-155.

MORAN, J. M. A educação que desejamos: Novos desafios de como chegar lá. 5. Ed. Campinas, SP: Papirus, 2012.

PIAGET, J. Seis estudos de Psicologia. Tradução de Maria Alice Magalhães D' Amorim e Paulo Sérgio Lima Silva. 24 ed. Rio de Janeiro: Forense Universitária, 1999.

PILETTI, N.; ROSSATO, S. M. Psicologia da aprendizagem: da teoria do condicionamento ao construtivismo. São Paulo: Contexto, 2011.

SALVADOR, A. D. Métodos e técnicas de pesquisa bibliográfica. Porto Alegre: Sulina Editora, 1991. SILVA, E. T. De como ser um mau professor/ de como ser um bom professor. In: . 0 professor e o combate à alienação imposta. São Paulo: Cortez, 1991, p. 3-12.

VEIGA, I. S. P. A. Docência como atividade profissional. In: VEIGA, I. P. A.; D'ÁVILA, C. M. (Orgs). Profissão docente: novos sentidos, novas perspectivas. Campinas-SP: Papirus, 2008, p. 13-21. 
ZABALA, A. A prática educativa: como ensinar. Porto Alegre: Artmed, 1998.

ZEICHNER, K. M. O professor como prático reflexivo. In: A formação reflexiva do professor: ideias e práticas. Lisboa: Educa, 1993, p. 13-29. 